\title{
STRESS COACHING 0.0. EXPERIMENTAL PROGRAMA DE COACHING PARA REDUCIR EL ESTRÉS
}

\section{STRESS COACHING 0.0. EXPERIMENTAL COACHING PROGRAM TO REDUCE STRESS}

\author{
José Jesús Vargas Delgado. Universidad Europea de Madrid. España.
}

\section{RESUMEN}

Bienvenido al programa Stress Coaching 0.0. Un práctico, e integrador viaje para reducir el estrés a su mínima expresión posible. En el capítulo profundizaremos en la esencia y en la metodología de nuestro programa Stress Coaching 0.0. de experiencia transpersonal, que puede serle muy útil para cualquier persona que experimente cualquier signo, o síntoma, de estrés como ansiedad, irritabilidad, tensión muscular, agotamiento, apatía, inquietud, dolor de cabeza, fatiga, problemas digestivos, dificultades de concentración, preocupación, exceso de trabajo, abuso de sustancias, tabaquismo, trastornos alimentarios, trastornos del sueño o simplemente sentirse abrumado por los eventos como por ejemplo todo lo vivenciado con el COVID-19. El Stress Coaching 0.0. también puede ayudarle a desplegar sus potenciales y lidiar con el estrés asociado con vivir con la enfermedad, dolor crónico y dolencias como artritis, asma, cáncer, fibromialgia, trastornos gastrointestinales, problemas cardiovasculares, hipertensión y migraña, entre otros. muchos.

PALABRAS CLAVES: mindfulness, meditations, mind, stress coaching, health, wellbeing.

\section{ABSTRACT}

Welcome to the Stress Coaching 0.0 program. A practical and integrative travel tool to reduce stress to a minimum. In this chapter we will delve into the essence and methodology of our Stress Coaching 0.0 program. of transpersonal experience, which can be very useful for anyone experiencing any signs or symptoms of stress such as anxiety, irritability, muscle tension, exhaustion, apathy, restlessness, headache, fatigue, digestive problems, concentration difficulties, worry, excess work, substance abuse, smoking, eating disorders, sleep disorders or simply feel overwhelmed by events such as everything experienced with COVID-19. Stress Coaching 0.0. It can also help you unfold your potentials and deal with the stress associated with living with the disease, chronic pain and ailments such as arthritis, asthma, cancer, fibromyalgia, gastrointestinal disorders, cardiovascular problems, hypertension and migraine, among others. Many.

KEY WORDS: mindfulness, meditations, mind, coaching stress, health, well-being. 


\section{Cómo citar el artículo:}

Vargas Delgado, J. (2020). Stress coaching 0.0. Experimental programa de coaching para reducir el estrés. Revista de Ciencias de la Comunicación e Información, 25(2), 71-90. doi: http://doi.org/10.35742/rcci.2020.25(2).71-90

\section{INTRODUCCIÓN}

El estrés sigue siendo, pese a la considerable investigación realizada en torno a él y a la ansiedad, y a los numerosos abordajes esbozados para afrontarlo y reducirlo, un aspecto inevitable de nuestra vida. El estrés siempre ha formado parte de la condición humana. Todos nos hallamos sumidos, sin escapatoria posible, en la incertidumbre de cada instante, COVID-19, los problemas, la enfermedad, la vejez, la muerte y la imposibilidad de controlar los acontecimientos en torno a los cuales gira nuestra vida. Y la situación llega a un extremo en que nos sentimos aislados y enajenados del mundo natural, sin saber cómo establecer el contacto con los demás con inteligencia de vida (Stahl y Golstein, 2010).

La tecnología, y un auténtico tsumani de información, han acelerado en los últimos años el ritmo y la complejidad de nuestra vida cotidiana. Los dispositivos electrónicos, el correo electrónico, whatsapp y las redes sociales nos mantienen conectados las 24 horas del día, los siete días de la semana, exponiéndonos a una verdadera avalancha de actividades y demandas diarias. Nuestro cerebro está abrumado por la aceleración del ritmo de la vida, y un auténtico bombardeo de información que nos expone a la frustración, preocupación, pánico, resistencia, autocrítica, autoexigencia y paciencia (García Campayo y Demarzo, 2019).

En este contexto no resulta sorprenderte, que muchas personas se preocupen, o se depriman tanto que, en un intento de recuperar el equilibrio interior perdido, se vean obligadas a solicitar 0 recibir medicación. $Y$ aunque este tratamiento pueda, en ocasiones, resultar necesario para recuperar la salud y el bienestar, también es importante cultivar los recursos internos de autocuidado que nos ayuden a enfrentarnos, con inteligencia cardíaca, más adecuadamente el estrés, dolor y la enfermedad.

En el capítulo desplegaremos una evocadora cuota del transformador programa Stress Coaching 0.0 . que se dirige a cualquier persona que conviva con el estrés, la ansiedad, el dolor o la enfermedad. De este modo el compromiso de la integración, e interiorización del programa en la vida cotidiana no solo te ayudará a reducir el estrés y la ansiedad a la mínima expresión, sino que se convertirá en una inspiradora ruta que puede orientarte con mente clara hacia el entrenamiento del logro de una vida más sana, fluida, tranquila y compasiva.

\section{OBJETIVOS}

Los cuatro objetivos y pilares esenciales de nuestro capítulo son los siguientes:

1. Compasión por nuestras emociones y estrés. El programa Stress Coaching 0.0. permite, a través de la compasión, aprender a respetar las emociones 
causadas por el estrés, para encontrar alivio, aceptar y recordar cambios emocionales importantes en nuestras vidas (García Campayo, 2019).

2. Enfoque consciente en nuestro cuerpo y manejo del estrés. A través de un estado de presencia profunda, permite aprender a enfocar la atención en la observación del cuerpo y en las sensaciones corporales, lo que produce una desactivación de los pensamientos que generan estrés, y un restablecimiento de la mente "atrapada", a través de una mirada interior.

3. Respira conscientemente. Con el ritmo de vida actual, no somos conscientes de que solemos realizar una respiración incorrecta y dispersa, y fragmentada. Por lo general, respiramos de manera acelerada, superficial e inconsciente. La aparición de diferentes problemas de salud comunes en las grandes metrópolis, como el estrés y la ansiedad, dificulta aún más el ejercicio presente y sistémico de la respiración.

4. Observación y comprensión de la naturaleza de nuestra mente. Aprenda a relacionarse con discernimiento con los pensamientos que causan estrés o que surgen como resultado de ellos. Comprender la naturaleza de nuestra mente y los fenómenos cognitivos. No podemos esperar modificar la naturaleza de nuestra mente, pero podemos convertirnos en observadores de la mente y evitar darle material para su "juego" de generar sufrimiento y estrés.

\section{METODOLOGIA}

Te recomendamos encarecidamente que cuando emprendas este viaje de comprensión profunda, lo hagas de manera secuencial. Porque su organización se atiende a un programa estructurado, bien establecido y eficaz. De este modo las lecturas enfocadas, las preguntas de autoindagación, las prácticas de interiorización y las propuestas de acción conscientes de cada contenido del programa, no solo te ayudarán a reducir el estrés y la ansiedad generados por los retos que la vida te depare, sino que se irán consolidando también con tu propia práctica.

No te preocupes si el cambio transformador no llega tan rápidamente como desearía, y ten en cuenta que, con el tiempo y práctica, acabará presentándose. No olvides que la clave del cambio real y duradero reside en la sabiduría de la práctica. Es importante que mantengas el ritmo diario, que apliques tu constancia y que seas firme en tu compromiso diario... Buen viaje Stress Coaching 0.0.

\section{DISCUSIÓN}

\subsection{Abraza con autocompasión al estrés}

El estrés es un tópico de gran popularidad porque afecta a un gran número de personas. Consiste en la respuesta automática y natural de nuestro organismo ante las situaciones que nos resultan amenazadoras, o desafiantes. En general, se tiende a creer que el estrés es consecuencia de circunstancias externas a nosotros, pero en realidad éste nace en nosotros, dependiendo de la forma en que evaluemos los sucesos o nuestras capacidades para hacerles frente. Cuando el estrés se prolonga o intensifica en el tiempo, nuestra salud, nuestro desempeño e incluso nuestras relaciones personales se pueden ver afectados (García Campayo y Demarzo, 2019). 
Una de las formas más eficaces de disolver con autoconsciencia el estrés viene a través de nuestra capacidad de aceptar su presencia, y ser capaz de abrazar nuestra ansiedad con compasión e inteligencia cardíaca. Paul Gilbert define compasión como la profunda consciencia del sufrimiento de uno mismo y de otros seres, junto con el deseo de ayudar a evitarlo. (Anchondo, 2012). De este concepto encontramos la autocompasión y sus efectos para la gestión del estrés. Autocompasión implica afecto, amabilidad y comprensión hacia uno mismo, cuando se experimenta sufrimiento ante una situación estresante, en lugar de autocriticarse, culparse o negar el propio dolor. Consiste en tratarnos a nosotros mismos tal y como trataríamos a un niño indefenso, o a un amigo muy querido. Lo contrario sería la autocrítica destructiva y culpabilizante (García Campayo 2015).

En general para la gran mayoría de los occidentales es más difícil darse afecto a uno mismo que darlo a otros. El gesto de abrazar a nuestro estrés de una forma amable, y proyectarnos autocompasión, en una situación contractiva, suele ser muy complicado de aceptar para nuestra mente dual. Para algunas personas esta práctica resulta prácticamente imposible. Unos, porque lo viven como una debilidad 0 un riesgo de convertirse en indolentes. Otros, porque no se consideran dignos de recibir afecto por parte de otros (frecuentemente, porque no lo recibieron de forma incondicional en la infancia). Si esta práctica nos resulta muy complicada, un truco efectico es iniciar la práctica de la compasión hacia los amigos y, cuando estemos dando afecto a personas que queremos, podemos incluirnos nosotros en la imagen, y darnos afecto a nosotros mismos también.

Abraza con amabilidad a tu estrés a través de un gesto compasivo sobre tu cuerpo para aliviar sus síntomas. La práctica de compasión que te proponemos para disolver el estrés busca regular el estrés activando el sistema de satisfacción, calma y seguridad. En autocompasión hay ciertos tipos de gestos, relacionados con el abrazo y el contacto, que liberan oxitocina, es decir, que nos tranquilizan.

Los principales desencadenantes de la autocompasión vinculados al estrés, son tres:

1. Contacto corporal suave.

2. Vocalización en tono suave.

3. Sensación de calidez a nivel físico.

Te invitamos a poner en marcha el gesto compasivo que puede ser muy útil para tranquilizarnos en momentos de estrés, o simplemente para sentirnos mejor en cualquier momento, o escenario de nuestra vida personal y/o profesional (García Campayo y Demarzo, 2019).

1. Ponerse una o dos manos en el corazón o en la zona central del pecho.

2. Poner una mano en el corazón o en la zona central del pecho, y otra en el abdomen.

3. Abrazarse a uno mismo, y acariciarse los brazos.

4. Abrazarse a uno mismo, y acariciarse la espalda.

5. Poner ambas manos cruzadas en el bajo vientre.

6. Cruzar los brazos, y acariciarse sin llegar a abrazarse.

7. Darse palmadas en el hombro, con una u otra mano, o con ambas. 
8. Acariciarse las piernas a diferentes niveles: muslos, gemelos.

9. Acunar amable la cara con ambas manos abiertas.

10. Acariciarse el dorso de las manos, frotarse las manos; tocarse las yemas de los dedos de ambas manos.

11. Acariciarse la mejilla.

12. Acariciarse el pelo de la cabeza.

13. Acariciarse la frente.

\subsection{El secreto de estrés $0:$ impermanencia y no verídico}

Cualquier fenómeno mental o emocional, o cualquier fenómeno estresante, si no lo potenciamos (pensándolo sobre ello, rechazándolo, o luchando con él) y simplemente lo observamos de forma desapasionada, como un fenómeno externo que perteneciese a otra persona, va a desaparecer. Este es el gran secreto de la gestión emocional orientada a la disolución del estrés en nuestro ser. Cualquier pensamiento o emoción que nos genere estrés o ansiedad, independientemente de su contenido y por terrible que parezca en este momento, acaba por desaparecer espontáneamente en poco tiempo. Por supuesto, que va a tener momentos intensos de influencias, pero tiene un proceso interno y tiene su ritmo profundo (García Campayo y Demarzo, 2019).

Se ha comprobado que existe un ciclo interno de las mareas emocionales. El ciclo suele extenderse a tiempo muy determinado como las mareas en el mar. Concretamente cada 45-90 minutos se ha investigado que existe un cambio de marea cognitiva y emocional, y de igual manera se produce un cambio en la frecuencia en los procesos que nos generan estrés. Es decir que, en los procesos mentales, cualquier pensamiento que podamos tener en la pantalla imaginaria de nuestro ser, es absolutamente impermanente. No tiene identidad y anclaje para mantenerse en el tiempo. Lo importante es no potenciarlo con nuestro apego, o nuestra lucha interna y ansiosa. Curiosamente cuanto más intentemos luchar con una emoción, un sentimiento en nuestro cuerpo, o un pensamiento, mayor es la permanencia en nuestro ser. De alguna forma estamos alterando la naturaleza y el ciclo de vida de cada pensamiento. Cada 45-90 minutos existe un cambio ciclo en la marea cognitiva y emocional (Vargas, 2019).

Pero lo importante es que cuando percibamos el despliegue súbito de una marea intensa delante de nosotros no intentemos ni generar pensamientos rumiantes sobre su aparición, ni resistirnos, ni luchar con ella. Es una manera de aceptar con mente clara el momento presente, y observarlo de la manera más desapasionada posible. Te invitamos a que lo percibas como si fuera un fenómeno externo que perteneciera a otra persona, porque finalmente el estrés va a desaparecer.

Por tanto ¿para qué hace falta cambiar ese fenómeno cognitivo por otro más positivo? ¿para qué queremos saber cómo se origina ese pensamiento concreto? ¿para qué tenemos que luchar con ese pensamiento estresante o emoción intentado racionalizar su disolución? ¿para que luchar con esa emoción o sentimiento que tengo asentada en una parte de mi cuerpo? 
Nuestro objetivo y nuestra propuesta es esperar a que desaparezcan sin dejarse atrapar por ellos. Además, otras de las características de la naturaleza de nuestra mente es que los pensamientos, o los fenómenos cognitivos no son ciertos, y por supuesto los procesos estresantes tampoco lo son.

No verídicos: Los fenómenos cognitivos y emocionales estresantes no son verídicos. Lo que pensamos no es la realidad externa, no es lo que ocurre. Si pensamos que somos unos "inútiles" no quiere decir que lo seamos. Si pensamos que el mundo es "horrible" o que somos incapaces de "hablar en público", o que tal persona es "malvada" no quiere decir que sea así, ya que otras muchas personas lo ven de forma diferente. Si podemos separar la realidad de nuestros pensamientos, no actuaremos sobre la base la información errónea que nos dice nuestra mente dispersa.

\subsection{Ilumina tu ser}

Cuando te sientes estresado tienes muchas más posibilidades de centrarte en lo que va mal. Así funciona nuestro cerebro bajo la influencia del estrés: busca amenazas $\mathrm{y}$, por lo general, las sobrevalora. Trae a tu mente la última vez que viste alguien estresado: ¿mantenía la calma si algo salía mal, o exageraba lo negativo, haciendo una montaña de un grano de arena? Nuestro cerebro en episodios estresantes le encanta realizar hipérboles y exageraciones de la percepción de la realidad. Aparece la mente discursiva y narrativa profundizando y ampliando las dificultades a modo de lupa gigantesca (Kabat-Zinn, 2007).

Es importante que nuestra intención en este camino de sanación del estrés consista en incorporar una sabia actitud positiva de autocuidado, y autodescubrimiento que ilumine todo nuestro ser. Pera ello es importante una intención de luz en todo lo que somos, en nuestra esencia. Aceptación profunda de todo nuestro ser, y por supuesto de nuestro estrés. Es posible que estés pasando por una fase en tu vida con muchas dificultades importantes, y que ni siquiera puedas pensar en nada positivo. Pero te animo a que intentes en esforzarte con plena aceptación a poner el foco de luz, y tu mirada interior, en tus cosas positivas. Deposita tu atención en todas las cosas buenas que tienes.

llumina tus bondades. Buscar las cosas buenas en tu vida es iluminar con creatividad cada uno de tus pasos recordándote como un mantra la infinidad de cosas buenas que tienes alrededor de tu vida (Vargas, 2014). Probablemente si estás pasando una época de mucho estrés es posible que lleves unas gafas oscuras condicionantes que no te permita discernir con claridad la realidad, ni el sentido de la situación de ansiedad que estas experimentando. Entramos en una fase de pensamientos negativos cíclicos que se van retroalimentando (rumiación). Nuestra propuesta en este proceso reside en poner la intención en ver las cosas de un color distinto y no creernos en absoluto lo que nuestra mente nos dice en cada momento. Una manera de percibir con inteligencia transpersonal y conciencia profunda la vida (Vargas, 2019).

Poner la intención en nuestras bondades y en todas nuestras cosas positivas es un pasaporte sagrado y emocional que nos permite adentrarnos en nuestro programa 
con una actitud creativa y elevada de energía. Una manera de tomar consciencia de dónde estamos, y de nuestra esencia como ser (Stahl y Golstein, 2010).

Para ello te invito a que respondas con honestidad en este momento, y con realismo, a las siguientes preguntas:

1. ¿Cómo eres en tus mejores momentos?

2. ¿Cómo eres cuando te sientes relajado?

3. ¿Por qué te sientes agradecido ahora mismo?

4. ¿Qué te hace feliz, ahora o en el pasado?

5. ¿Qué te entusiasma o emociona?

6. ¿Qué te va bien en tu vida ahora mismo?

7. ¿Qué te hace disfrutar ahora o en el pasado?

La toma de consciencia de nuestras bondades es una manera de darse cuenta de la luz que tiene nuestro ser y nuestro despliegue infinito de potenciales perennes. Al hacernos conscientes, e incluso verbalizarlas, o escribirlas, conseguimos que se genere un proceso de anclaje, reconocimiento y materialización en todas nuestras infinitas bondades.

\subsection{Los 4 pilares de tu templo: pies, espalda, manos y cara}

Tradicionalmente, el cuerpo ha sido negado en occidente, lo que le ha dado mayor preponderancia a la mente. La mente ha sido considerada como el lugar donde se produce la vida intelectual, la vida imaginativa y narrativa. $Y$, por supuesto, se ha pensado que todo el proceso para la disolución del estrés tiene su foco exclusivamente en la mente. Y por esa razón, siempre en occidente se ha pensado que el cuerpo es simplemente un vehículo o soporte complementario dirigido por la mente (García Campayo, 2019).

La cultura oriental siempre ha mantenido una posición diferente, considerando la conexión con el cuerpo tan importante como la mente para el equilibrio del individuo. Las investigaciones actuales respaldan la hipótesis de la enorme importancia del cuerpo en nuestra psique, y en nuestra forma de integrar, re-cordar, y poder afrontar de forma sana los cuadros de estrés y ansiedad.

Se demuestra que las percepciones interoceptivas (conciencia sensaciones corporales) modifican nuestros pensamientos y emociones de una manera importante y viceversa. De hecho, hay estudios que muestran que, si se modifica la postura habitual, simplemente introduciendo un lápiz en la boca, e introduciendo la sonrisa, uno encuentra las experiencias y la narración más divertidas (por ejemplo, leer una historia cómica) que si es no se ha realizado esta modificación.

El cuerpo, nuestra postura y la respiración, por lo tanto, se conforman como una variable esencial cuando se trata de la emoción y la percepción de los pensamientos que generan estrés. Desde la perspectiva de mindfulness, que consiste en estar atentos al momento presente, el cuerpo y la respiración son clave porque siempre están en el presente. Por ello, son los puntos de anclaje preferidos. Las emociones y los pensamientos estresantes no serán útiles como puntos de anclaje porque se 
encuentran más frecuentemente en el pasado y en el futuro, que en el absoluto momento presente.

Por todo ello dirigir la atención y la conexión a nuestro cuerpo, resetea la mente, permite que salga de los bucles rumiativos, y se paran los procesos de pensamientos estresantes. Habitualmente lo que hacemos es perdernos en los continuados pensamientos estresantes asociados a las emociones, lo que genera más emociones en un ciclo interminable (Wallace, 2006).

Desviar el foco de nuestra atención a nuestro cuerpo y en las sensaciones corporales de la emoción cargada de estrés, permite desactivar los pensamientos negativos asociados, y ablandar los síntomas corporales nucleares del estrés en las emociones. Un sabio proceso de crecimiento integral través del cuerpo (García Campayo, 2019).

- Pies: primer pilar de tu templo. Cuando estés de pie toma consciencia de la postura. Percibe el enraizamiento de tu cuerpo a la tierra. Toma consciencia del contacto firme de tus plantas sobre la tierra y el anclaje que supone. Cuando estés sentado percibe como tus pies están plenamente conectados con la tierra. Es un canal de conexión con nuestra esencia. Siente como están abiertos y relajados, lo que inducirá una sensación psicológica acorde.

- Espalda: segundo pilar de tu templo. Tu espalda, debe permanecer recta, pero en una postura cómoda. La espalda determina nuestro nivel emocional. Imagina que un hilo invisible tira desde la coronilla y deja que esté amplia y en apertura. Es el pentagrama de las emociones, así que intenta que estén en generosa expansión para escuchar todos los matices.

- Manos: tercer pilar de tu templo. Es importante que no estén tensas. Que descanses cómodamente sobre las piernas para evitar molestias sobre los hombros. La tensión de las manos se considera un indicador de la tensión mental y un espacio de manifestación del estrés.

- Cara: cuarto pilar de tu templo. Es importante que en la cara no haya tensión como suele ser habitual. Hay que relajar la frente, los párpados y los labios, así como la zona donde la lengua se apoya en el paladar. Todas son zonas de frecuente tensión en momentos de estrés.

\subsection{Planeta 9 "hacer" y planeta 0 "ser"}

Actualmente consideramos que existen dos formas básicas de funcionamiento de la mente humana. Dos sistemas operativos, que tiene una incidencia directa con nuestra relación con el estrés y con la ansiedad. Modo "hacer" y modo "ser", que son característicos, pero no absolutamente específicos del pensamiento occidental y oriental, respectivamente. Se basan en premisas totalmente diferentes (García Campayo, 2019).

- Planeta 9 "hacer". El pensamiento occidental en modo hacer, planeta 9, será basado en la creencia de que la felicidad está fuera de nosotros. Sentimos que hay algo que alcanzar: dinero, poder, relaciones sociales o familiares, posición laboral de reconocimiento, éxito en un proyecto, y pensamos de manera directa, causal y sencilla, que cuando lo tengamos, seremos felices. 
La historia de todos los que residen en el planeta 9 del modo "hacer", es la búsqueda continua de metas/objetos que pensamos que nos pueden hacer felices: una carrera universitaria, un trabajo prestigioso, una pareja, hijos, posesiones, viajes, reputada posición social., ... El problema es que cuando conseguimos cualquiera de estos elementos, incluso algo tan ansiado como es el premio gordo de la lotería, los estudios confirman que, en un plazo de 6 a 12 meses, los individuos vuelven al nivel de felicidad anterior a que se consiguiese el objeto. La conclusión es que nos vemos involucrados en un proceso interminable de búsqueda de felicidad, pero nunca la alcanzamos de forma estable. Por supuesto, esta búsqueda continua, e insaciable de objetivos, es una de las principales causas del enorme estrés al que estamos sometidos en la vida actual. El planeta 9 "hacer" se asocia a la visión del "yo biográfico", porque los objetivos que nos marcamos se asocian a las etiquetas o descripciones de nosotros mismos que hemos ido desarrollando a lo largo de la vida y con las que nos identificamos. La etiqueta del 9 como una manera metafórica de representar la idealización del "modo hacer" (Vargas, 2019).

- Planeta 0 "ser". El pensamiento oriental parte de la base de que la felicidad no está fuera de nosotros, sino dentro. No hay nada que perseguir, nada que obtener. Solo re-cordar a través de la inteligencia cardíaca de nuestro planeta "ser" Todo está en el presente, que es lo único importante, ya que pasado y futuro no existen. La forma de alcanzar este estado de la mente es mediante el enfoque de la aceptación, que se considera la principal cualidad que se desarrolla con la atención plena (Shamash, 2015). La aceptación es un concepto que, generalmente, repele a los occidentales porque lo confunden con resignación, una característica asociada a nuestra tradición judeocristiana. Pero la resignación ocurre conceptualmente en el futuro. Consistiría en la renuncia a actuar en el futuro porque va a ser inútil. Por el contrario, la aceptación ocurre siempre en el presente. Desde el planeta 0 "ser" aceptamos plenamente el estrés, pero no nos resignamos. Se basa en la idea de que lo que está ocurriendo en el momento presente, dado que no podemos cambiarlo, hay que tomarlo, y aceptarlo como viene entregándose a él sin evitarlo, lucharlo o negarlo. En el planeta 0 "ser", proponemos sumergirnos incondicionalmente en lo que trae el presente. Aceptar el presente no significa que nos guste lo que ocurre, sino que aceptamos que no podemos cambiarlo. Toma plena consciencia, desde qué planeta estás viviendo cada instante, y desde qué planeta estás interpretando los procesos estresantes que estás vivenciando (Vargas, 2019).

\subsection{Velero experiencial de tu respiración}

Si tu mente parlotea descontrolada, y tus sentimientos dan vueltas como una sopa en pleno hervor, has de saber que no estás solo. En nuestra agitada y exigente sociedad moderna, activa permanentemente, la estimulación constante, las decisiones y los desafíos provocan pensamientos y emociones. $Y$ cuando estamos en esa situación de ansiedad, tenemos muchas más posibilidades de reaccionar de manera automática (e inútil) a los factores estresantes de la vida.

Un excelente modo de gestionar los pensamientos consiste en utilizar la respiración. Recurrir a la atención plena de la respiración para afrontar el estrés, puede parecer 
algo demasiado simple, pero te invito a que lo pruebes antes de activar cualquier juicio. El efecto calmante se produce gracias al uso de la respiración para anclarte en el momento presente. Y cuanto más utilices la respiración para volver al presente, más sencillo, transformador y más efectivo resultará el método.

Tómate un momento para pensar en un ancla: su función consiste en evitar que el barco vaya a la deriva. Que tu velero se conecte con la tierra. El ancla siempre está preparada en el barco, y cada vez que éste zarpa, el ancla va con él. Cuando el velero tiene que detenerse, alguien lanza el ancla al agua. El ancla es tu respiración, y siempre está en el barco preparada para tomar tierra cuando lo necesites (Vargas, 2019).

Del mismo modo, vayas donde vayas, tu respiración siempre va contigo y se despliegan tus potenciales con su presencia consciente. Por suerte, no puedes huir de tu respiración o dejártela en casa cuando sales a pasar el día fuera. La respiración va siempre contigo en todas tus experiencias y vivencias, noche y día. De lo que sí puedes olvidarte, es de prestar atención de vez en cuando a la sensación de la respiración. Pero siempre que desees realizar una pausa experiencial, puedes centrar tu atención en la respiración como ancla para devolverte al aquí y al ahora de tu velero, y de tu ser.

La respiración constituye una faceta fascinante del ser humano, una de esas funciones únicas de nuestro barco, que puede ser automática pero también, en parte, controlada y deliberada. Los latidos del corazón, por ejemplo, son distintos. El corazón late día y noche sin parar, pero no puedes hacer que deje de latir ni siquiera unos segundos; en cambio, sí que puedes detener la respiración. Tampoco puedes parar la digestión, o tu sistema inmunológico. Te invitamos en momentos de estrés a que pongas toda tu atención sobre la respiración. Una manera de conectarte con el ancla más auténtica de tu barco y de tu ser. Observa muy atento tu respiración cuando hables, y observa muy atento tu respiración cuando escuchas. La respiración es automática y, al mismo tiempo, está bajo control. Existen muy pocas funciones del cuerpo tan automatizadas que, además, puedas controlar.

Casi todas las técnicas de relajación hacen uso de la respiración profunda. El motivo es que la respiración está íntimamente ligada con el sistema corporal responsable de la relajación. Los sentimientos de relajación surgen casi siempre cuando se respira de manera lenta y profunda. La atención plena sobre la respiración es ligeramente distinta. Durante la respiración atenta no es necesario controlar el ritmo, o la profundidad de la respiración. Simplemente se trata de prestar atención a la respiración tal como es, sin juzgar. Experimenta en grandes momentos de estrés tomar de la mano a tu respiración, a través de tu atención, con curiosa atención, cariño y presencia. Observa y experimenta con tu mirada interior qué sucede.

\subsection{El fotograma de la gratitud: susurra a tus emociones}

Sorprendentemente, las investigaciones psicológicas realizadas en torno a este fenómeno, han concluido que, en realidad, el nivel de satisfacción con la propia vida no depende tanto ni de las circunstancias que vivimos, ni de la personalidad, o el 
carácter. Existe un factor más determinante en nuestra sensación de bienestar que muchas veces se nos olvida: La gratitud.

Está demostrado que ser agradecidos tiene muchas ventajas, la más importante de todas es que: la gente agradecida es más feliz. Especialmente práctico en los procesos estresantes. Sabemos que la llamada "realidad", y cómo nosotros la interpretamos, son dos cosas muy distintas. Lo que "sucede" no es lo que nosotros percibimos, ya que todas las experiencias de nuestra vida las vemos a través de unas particulares "gafas" que interpretan la realidad a "su modo de ver". En primer lugar, reconozcamos que todos nosotros llevamos esas "gafas de ver la realidad", y después, asumamos que, por lo general, estas gafas funcionan de un modo un tanto limitado (Doria, 2017).

Seamos honestos:

- ¿Acaso no tendemos a desestimar todo aquello podemos apreciar en nuestras vidas?

- ¿No tenemos una extraña facilidad para poner nuestra atención en aquello que nos resulta inconveniente?

Esta tendencia se refleja incluso en los medios de comunicación, que inciden constantemente en tragedias, problemas y catástrofes, obviando casi por completo los bellos aspectos de la vida que podemos apreciar.

Para comenzar a reconocer la abundancia de aspectos gratificantes que hay en nuestra vida, tenemos que darnos cuenta y reconoceros en un automatismo muy habitual en nosotros: "No saber recibir". No sabemos tomar todo aquello que de forma gratuita la vida nos ofrece, no nos creemos merecedores de recibir lo que nos viene dado "porque si", sin necesidad de haber luchado con sangre, sudor y lágrimas por ello.

Nos enfocamos en todo aquello que nos disgusta, que podría ser "mejor" o de otra manera, lo que nos conduce a un mar de quejas sin sentido, a sentirnos tristes y desalentados. Los escenarios de estrés son ejemplo absoluto de este proceso. Al expresar y sentir gratitud, eliminamos de nuestra mente el tóxico programa de las quejas. Un programa que nos induce a sentirnos víctimas de las circunstancias estresantes que vivimos, depositando así todo nuestro poder en "lo de fuera", sin responsabilizarnos de nosotros mismos y de nuestro bienestar. Cada vez que sentimos y expresamos interior o exteriormente: "gracias", estamos creando nuevas redes neuronales que se mantienen en el tiempo, debilitando aquellas relacionadas con el victimismo, el desaliento y la queja (Doria, 2017).

¿Te has parado a observar los pequeños detalles que de forma "gratis" la vida te ofrece a lo largo de cada día?: El amable tacto de la brisa por la mañana, el gratificante olor de una flor, la luz del sol, esa cena con tus amigos, la sonrisa que de pronto alguien te regala... si prestamos atención, podemos descubrir en cada instante multitud de detalles que realmente nos hacen sentirnos completamente vivos y despiertos, detalles, que podemos agradecer. Disponemos de muchas cosas, y no reparamos en lo agradecidos que podemos estar por ellas. ¿Te has 
detenido a observar lo agradecido que puedes sentirte por disponer de un techo bajo el que cada día cobijarte, del dinero suficiente para que todas tus necesidades básicas estén cubiertas, de los platos de comida de los que cada día disfrutas? ¿Aprecias ese amable saludo de tu compañero en el trabajo, ese abrazo inesperado, el interés de quien te pregunta cómo te encuentras o de quien te dedica una cómplice sonrisa? ¿Te das cuenta de lo que puedes agradecer que haya en tu vida personas en quienes puedes confiar? ¿Aprecias el mecanismo de la respiración en tu cuerpo que momento a momento de sostiene, el oxígeno que respiras cada instante, el regalo de estar vivo aquí y ahora?

Incluso en momentos de mucho estrés como, con la vivencia del COVID-19, si observamos bien, cada instante de la vida puede ser un instante de gratitud. Por muchos problemas que tengamos, si estamos atentos, es imposible no encontrar algo por lo que estar agradecidos. Para poder apreciar todo lo bueno que hay en nuestras vidas tenemos que estar "presentes" de verdad en cada instante, de este modo conectaremos con la constante abundancia y generosidad de la vida que vivimos.

La primera de ellas consiste en que durante el día de hoy mantengas la atención sostenida a dar las gracias, bien sea de forma interior o exterior, por cada detalle del día a día que puedes recibir con aprecio. Probablemente los procesos estresantes no te permitan vivenciarlo. Presta atención momento a momento a todo aquello que sucede que en verdad puedes reconocer y valorar (Doria, 2017). Si estas atento a la infinidad de cosas por las que puedes dar las gracias en cada vez en más momentos y a cada vez más personas, poco a poco comenzarás a sentirte merecedor de recibir lo bueno y bello de la vida, contactarás el profundo sentir de que, en verdad, la vida es más fácil y amable de lo que a veces has creído. Al sentir aprecio y gratitud cada vez más frecuentemente, todo aquello que rechazas y por lo que te quejas tendrá menos fuerza; será transformado por la mirada que tus nuevas y más amplias "gafas de ver el mundo" te ofrecerán.

La segunda práctica en este programa de Stress Coaching 0.0. que te proponemos constituye un poderoso ejercicio que, en poco tiempo, conlleva grandes cambios neurológicos y de reprogramación para tu mente.

Se trata de que cada noche, antes de acostarte, recorras en tu mente con todo detalle la "película de tu día". Recrea cada momento que has vivido en tu jornada desde que te despertarte a la mañana, enfocando tu atención en todo aquello que ha sucedido que puedes apreciar. Consigue una libreta o cuaderno y cada vez que encuentres un gesto, un detalle, un suceso, una persona por la que puedes estar agradecido (Vargas, 2019).

Susurra a tus emociones con amabilidad y cariño, conectando con la frecuencia de la gratitud. Experimenta a tratarte a través de un trato amable y amoroso. En un estado de calma y conexión contigo puedes experimentar qué sucede si te llamas internamente, como un susurro interno, por tu nombre con un tono duro, brusco y despectivo y puedes observar que sucede. Observa qué sucede en tu cuerpo si te llamas con brusquedad y de manera despectiva. Como si te dirigieras a ti. 
Ahora experimenta escuchar tu nombre de manera suave, amoroso. Es una manera de decir internamente a través de un susurro sutil y delicado. Puedes experimentar qué sucede en tu cuerpo. Cuando susurramos nuestro nombre hacia nosotros mismo podemos ver cómo cambia nuestra frecuencia y nuestro estado de vibración. Muy recomendable realizarlo en procesos de estrés.

\subsection{Gran cámara cenital consciente}

Atención plena podría definirse como el proceso de desarrollar el observador, es decir, de desarrollar metacognición. Una gran cámara cenital, en gran formato de silencio, que visualice toda la narrativa desde una perspectiva sana. Es la técnica de escindir la mente de forma que una parte de ella, el observador, se haga consciente de los objetos de la mente, sin identificarse con ellos. En las fases iniciales, el observador y la cámara cenital es muy débil y los objetos muy potentes, por lo que tiende fácilmente e identificarse con ellos, especialmente en momentos de ansiedad. Con el paso de los meses el observador se robustece y los objetos mentales se van diluyendo (Doria, 2017).

Con el fortalecimiento la gran cámara cenital, o el observador testigo, van a ocurrir tres fenómenos de la mente que nos permite conectar con una comprensión transformadora elevada:

- Cada vez hay menos pensamientos estresantes. Al no identificarnos con ellos, les falta gasolina, pierden fuerza. Cuando aparece un pensamiento (por ejemplo: "no voy a poder afrontar este reto que me han asignado") no se genera un racimo de pensamientos concatenados (por ejemplo: "seguramente mi jefe se dará cuenta que no soy la persona adecuada para afrontar este reto", o "no soy capaz de afrontar todo lo que se me ha asignado", "voy a defraudar a las personas que han confiado en mí", ...

- Cada vez hay más huecos entre pensamientos de ansiedad. Al haber menos pensamientos es más fácil ver que existan huecos entre pensamientos, algo imposible de hacer consciente antes de practicar meditación. En las tradiciones contemplativas, se insiste al practicante en buscar los huecos entre pensamientos, porque la auténtica naturaleza de la mente. Espacio entre los fenómenos estresantes.

- Cada vez nos creemos menos los pensamientos de alteración. Somos conscientes de que son solo fenómenos mentales, que no son la realidad, que no lo hemos generado nosotros voluntariamente y que, si no les ponemos atención, desaparecerán de la mente en pocos segundos.

\subsection{La historia interminable de nuestra mente}

Ya sabes que un aspecto fundamental de la naturaleza del estrés es que los pensamientos, que crees absolutamente ciertos, te asaltan de repente y se recrean en tu mente de manera continua. Si tus pensamientos te sugieren que todo va a bien, y que tienes el control, tus niveles de estrés se mantienen a raya. En cambio, si tus pensamientos se obsesionan con lo negativo, y te hacen sentir que has perdido el control, tus niveles de estrés aumentan, y el diálogo interno se hace casi interminable en la pantalla de tu mente (Vargas, 2018). 
Por lo general, los pensamientos adoptan en tu cabeza la forma de pequeños relatos y anhelos: El discurso de la mente: storytelling cognitivo. Desde que el hombre es hombre, los relatos van pasando de generación en generación, y conectan con el alma humana. La literatura está llena de relatos, desde las fábulas de Esopo hasta las obras de Shakespeare. Los historiadores conjuran imágenes de antiguas culturas narrando historias en torno a una hoguera, en un entorno para compartir y nutrir. Imagina que el cerebro es una máquina de narrar historias. Lo llamamos storytelling cognitivo. Es una especie de fábrica de historias que no tiene fin. Desde el momento en que te levantas por la mañana, empiezas a explicarte la historia de tu vida. En el segundo inmediatamente después de despertarte estás presente y nada más, sin tu historia. ¿Lo has notado alguna vez? Pero entonces de repente, tu historia personal invade tu consciencia, por lo general sin que te des cuenta. Tu cerebro te recuerda quién eres, dónde vives y qué tienes que hacer, Se trata de un proceso automático. Es una producción inacabada de historias cada instante.

Toma consciencia de la naturaleza de los pensamientos discursivos de la mente. Atención para discernir la rumiación de la película de la mente frente a la presencia estable de tu pantalla. Te relatas historias continuamente sobre todo tipo de personas, situaciones hechos y dificultades. Comienzas a dibujar en el lienzo de tu mente, y a trazar dibujos narrativos continuamente. Si tomas consciencia de que te estás narrando un relato sobre una determinada situación estresante, podrás sopesar si la historia que cuentas es realmente cierta (Vargas, 2019).

Tu identidad se construye de dos maneras: con historias construidas a lo largo del tiempo, o mediante tus experiencias con la experiencia directa. Si te preguntase quién eres me dirías tu nombre. Si te volviese a preguntar me contarías tu historia: dónde naciste, en qué trabajas, qué haces en tu tiempo libre, etc. Pero también puedes sentir quién eres sin tu historia. $Y$ para ello tienes que conectarte con tus sentidos. Es una manera de conectar con tu esencia.

El cerebro narrador es una red que se activa por defecto, que incluye su actividad en la parte del cerebro responsable de la memoria. Cuando haces cola en un centro comercial, tu mente se dispersa, fantasea y se preocupa. Sin embargo, esa red también se activa fácilmente cuando vas un paseo por el parque. En lugar de ver la belleza que te rodea, te quedas atrapado en tu pequeño mundo de preocupaciones e historias internas. Es el relato interminable que te cuentas a ti mismo sobre tu propia vida, las vidas de las personas que conoces, y nuestras interacciones. No hay nada de malo en la parte de tu cerebro basada en la narrativa. Pero nadie quiere limitar su vida a su narrativa personal, ya que resulta muy sencillo perderse en pensamientos y emociones negativas, si no prestamos atención al momento presente. En situaciones de estrés si nos perdemos en el argumento interno de la historia interminable de cada narración de nuestra mente, las posibilidades para aumentar los niveles de ansiedad aumentan considerablemente (Kabat-Zinn, 2007).

Cada vez existen más pruebas científicas de que cuanto más tiempo pasamos perdidos con los relatos que narra nuestra mente, más propensos somos al estrés y la ansiedad. La manera de desactivar la identificación con la narración de la historia interminable de nuestra mente es a través de la activación de nuestra atención sobre 
la experiencia directa y sobre nuestros sentidos. Una manera de discernir la narración interminable, del momento presente. Esa activación de la experiencia directa es un estado de atención plena. Vives en el momento presente. Es el funcionamiento del "modo ser". Cuando paseas por el parque, percibes el aroma de los árboles, el color de las flores y las sensaciones de tu cuerpo. Especialmente en momentos de estrés, te proponemos que actives la experiencia directa sobre la activación del cerebro narrador de la historia interminable de tu mente.

\subsection{Lego de emociones. Construye las emociones en tu cuerpo}

Los sentimientos son la experiencia consciente del estado del cuerpo. No solo se corresponden con hechos, también pueden originarse en representaciones cerebrales (pensamientos e imágenes), es decir sentimientos diferentes de los que correspondería de forma habitual a lo que está ocurriendo y por ello podemos decidir que sentimientos elegir.

Las emociones son reacciones puntuales, reactivas, arraigadas al cuerpo, de corta duración, automáticas y se manifiestan con distinta intensidad. A diferencia del estado de ánimo, que se retroalimentan con el diálogo interno de nuestra mente. Todas las emociones son tremendamente útiles. Es la magia de la sencillez de las emociones. De hecho, no existen las emociones positivas ni las negativas. Las emociones son expansivas y contractivas, pero todas encierran un profundo mensaje sobre nuestro ser, que es importante que escuchemos con atención plena para poder descubrir y descifrar su contenido. Desde esta perspectiva la relación con nuestras emociones debe ser de una apertura y celebración porque la llegada de cada una de ellas, incluidas las estresantes, tienen una demostrada y trascendente función y un autodescubrimiento (Saki y Santorelli 2016).

Todas las emociones son profundamente útiles y aparecen para ser comprendidas en un nivel de consciencia elevado. El lienzo de las emociones no está en la mente, está en el cuerpo. Toda emoción se manifiesta siempre en el cuerpo, y ese es su modo de existir. Las emociones estresantes surgen a través de nuestros pensamientos, pero finalmente alcanzan su plenitud compositiva a través de la producción y el asentamiento en el cuerpo. Es el hábitat de las emociones. Cuando estamos viendo una película de miedo y sentimos una emoción de miedo, esa emoción siempre va al cuerpo. Esa emoción va a una zona de cuerpo en la que se siente cómoda y se hace fuerte. Nuestro cuerpo es como un parador, y las emociones de manera libre encuentran una habitación y un lugar donde instalarse, y por supuesto una morfología (Vargas, 2019).

La manera sana de gestionar las emociones estresantes que se asientan en nuestro cuerpo no es la de luchar con ellas. No puedo negar la presencia de una emoción de ansiedad porque lo decida mi mente, o como una orden. De hecho, cuanto más luche por que una emoción se vaya del centro de nuestro ser, más grande y fuerte se hace la emoción en nuestro parador. Es como luchar con una ola, no puedo luchar con ella tengo que mirarla a los ojos, aceptarla, e intentar surfearla son fluidez. Mirar a los ojos a la emoción es el primer paso para poner en marcha de la 
disolución de las emociones estresantes que se asienten en nuestro cuerpo (Vargas, 2019).

Las emociones estresantes, como piezas de un lego imaginario, tienen forma, textura, peso, olor, temperatura, profundidad, morfología y color. Experimenta con ellas como primer paso de la aceptación profunda. Como las piezas de un lego, la formalización y manifestación de las emociones permite una experimentación experiencial de los sentimientos en nuestro cuerpo. Cuando tomamos conciencia de la forma de las piezas de una emoción estamos amando su presencia, y es una manera de inclinarnos ante ella permitiendo su identidad profunda y su morfología en nuestro cuerpo (Vargas, 2019).

El objetivo principal de la recreación narrativa de la forma de las emociones es el aumento de la conciencia sobre la emoción a trabajar, a través de las sensaciones corporales. Si materializamos las emociones y enfocamos nuestra atención en las sensaciones corporales que éstas generan en nuestro cuerpo, hay una disminución irremediable en el diálogo interno, que es la principal causa del estrés. Hay una mayor conciencia de los procesos corporales, como la respiración, la postura, el movimiento o la escucha de sonidos. Los sonidos aparecen geolocalizados. Lo que vemos y experimentamos aparece con una tridimensionalidad y un brillo especial. Un ejemplo de esto es percibir una emoción como el miedo con un color gris, con la forma de un ancla muy pesada, con una temperatura fría y con una áspera textura.

\section{CONCLUSIONES}

Enhorabuena por haber llegado al final de la primera fase de este trasformador viaje Stress Coaching 0.0. de autodescubrimiento, crecimiento y mirada interior. Pero por más que éste parezca el final de una primera temporada, no es, en realidad, más que otro evocador paso de autoconsciencia hacia adelante, en dirección a un compromiso y nuevo estilo de vida. La práctica te permitirá, a medida que avances, cultivar y entrenar niveles de autocomprensión y compasión cada vez más profundos, y gestionar con inteligencia de vida, y de un modo más activo, y eficaz, tu salud y bienestar. Este ajuste a las necesidades de la persona puede darse por medio de la Inteligencia Emocional, buscando conocer mejor el comportamiento del usuario a través de sus emociones con la finalidad de satisfacer sus deseos y demandas (Barrientos, Barquero y Terceño, 2019). Cuanto más claramente puedas identificar y discernir, las situaciones estresantes y estar atento a ellas, antes podrás desenredarte, y desapegarte, de las reacciones automáticas y de las trampas de la mente, lo que te abrirá las puertas a nuevas posibilidades y a respuestas más adecuadas e inspiradoras (García Campayo 2015).

Una de las mayores dificultades en la práctica de nuestro programa Stress Coaching 0.0. consiste en incorporar la práctica en el día a día, y mantenerla durante toda la vida. Este problema del mantenimiento vivo de este proceso a lo largo de los años no ocurre solo en nuestro programa, sino en otros muchos ámbitos, como los hábitos de la vida saludable (ejercicio físico regular, dieta saludable), actividad artística (práctica con algún instrumento musical, teatro, danza) y, prácticamente, en 
cualquier actividad humana. En los primeros meses, la práctica suele ser intensa y frecuente, pero, con el tiempo, va espaciándose cada vez más y acortando su frecuencia y duración. Siempre acabamos encontrando razones que justifican el abandono de la práctica. Este proceso es comprensible, porque en la vida podemos elegir entre múltiples actividades que pueden resultarnos satisfactorias, por lo que resulta difícil elegir entre ellas, ya que el tiempo vital es limitado. Las recaídas de nuestros niveles de estrés se considera una fase más del proceso de curación y sanación. Todo lo que nos sucede aparece para ser comprendido, y debemos mantener una frecuencia de sabiduría transpersonal que permita comprender que gran parte de las vivencias se convertirán en transformadoras semillas que florecerán cuando tengan que hacerlo (Doria, 2017). De la misma manera el abandono de la práctica de nuestro programa debería ser considerado como una fase más del proceso de aprendizaje, y habría que prepararse para cuando llegue, empleando medidas preventivas desde el primer momento.

- Medidas preventivas para mantener la práctica del programa Stress Coaching 0.0 .

1. Relacionadas con la motivación: para que el programa se mantenga en el tiempo, debe tener un puesto maduro y relevante dentro de nuestros valores y de nuestro sentido de vida. La experiencia nos enseña que las personas que mantienen la práctica del programa durante años son las que tienen un claro sentido de vida vinculado a la práctica.

2. Relacionadas con la expansión: una excelente y sana manera de mantener la práctica consiste en su propagación y expansión, con el fin de una mejora del bienestar global y la calidad de la vida de nuestro entorno.

Cuando por diferentes causas no puedes seguir las prácticas del programa, recuerda con mente clara y profunda aceptación, mantener una actitud curiosa y amable para regresar al camino de la presencia, en vez de tomártelo como un factor estresante más.

Gracias por realizar con nosotros este transpersonal viaje de Stress Coaching 0.0. Nos sentimos profundamente honrados de que hayas compartido con nosotros esta primera fase del proceso vital desde dentro. Recuerda que, por muy malo que sea tu pasado o muy desalentador que parezca tu futuro no estás solo, y puedes encontrar alivio en el momento presente. Ante la ansiedad y el estrés agudo tómate la vida momento a momento, respiración consciente a respiración consciente. La coherencia cardíaca, la alegría, la paz y la comprensión transformadora realmente están a tu alcance. Te deseamos toda la felicidad del mundo.

\section{REFERENCIAS}

Anchondo, H. Ramos, N. y Recondo, O. (2012). Inteligencia emocional completa: atención plena y manejo efectivo de las emociones. Editorial Kairós.

Barrientos-Báez, A., Barquero-Cabrero, M., y Rodríguez-Terceño, J. (2019). Educación emocional como contenido transversal para una nueva política educativa: el caso del Grado de Turismo. Utopía y Praxis Latinoamericana, año: 24, no extra, 4, 147-165. ISSN 1315-5216. 
Clínica Onelife. [Internet]. 2016. Disponible en: https://onelife.es/ [Acceso: 2019-1224].

Doria, J. (2017). Sabiduría de la vida simple. Editorial La esfera de los libros.

Doria, J. Las 40 puertas. (2016). Un camino hacia la inteligencia transpersonal y la atención plena. Editorial La esfera de los libros.

Escuela transpersonal. (2019). [Internet]. Disponible en: https://escuelatranspersonal.com/ [Acceso: 2019-12-24].

García Campayo J, y Demarzo, M. (2015). Atención plena y compasión. La nueva revolución $1^{\underline{a}}$ ed. Barcelona: Editorial Siglantana, 19-29.

García Campayo, J. (2019). La práctica de la compasión. 1a ed. Editorial Siglantana.

García Campayo, J. y Demarzo M. (2015). Mindfulness. Curiosidad y aceptación. 1aㅡ ed. Editorial Siglantana.

García Campayo, J. y Demarzo M. (2018). ¿Qué sabemos sobre Mindfulness? 1a ed. Editorial Kairós.

García Campayo, J. y Demarzo M. (2019). Mindfulness nuevo manual práctico. 1aㅡ ed. Editorial Siglantana.

Germer, C. (2005). Enseñar la atención plena en la terapia. 1aㅡ Editorial Prensa de Guilford.

Kabat-Zinn, J. (2007). Viviendo la crisis por completo: Cómo usar la sabiduría del cuerpo y la mente para lidiar con el estrés, el dolor y la enfermedad. Editorial Kairós, (Full Catastrophe Living: Usando la sabiduría de su cuerpo y mente para Estrés facial, dolor y enfermedad, Delta, 1991), 205-219.

Kabat-Zinn, J. (2009). La atención plena en la vida cotidiana: Cómo descubrir las claves de la atención plena / Donde quiera que vayas, allí estás, Ediciones Paidós Ibérica. (Dondequiera que vayas, allí estás: Meditación de atención plena en la vida cotidiana, Hyperion, 1994).

Kabat-Zinn, J. (2016). El poder curativo de la atención plena: una nueva forma de ser. Editorial Kairós.

Kabat-Zinn, J. (2017). La práctica de la atención plena. $1^{\text {a }}$ ed. Editorial Kairós.

Saki, F. y Santorelli. (2016). Programa MBCP para la conciencia perceptiva, y la profundidad integral del arte inspirado en Cervantes. En: Congreso internacional La recepción de Cervantes en los siglos XX y XXI. Mitos y leyendas; 5-7 de octubre de 2016.

Shamash, A. (2015). Batir el estrés con atención plena. 1aㅡ ed. Editorial Espasa books. 
Stahl, B y Golstein E. (2010). Atención plena para reducir el estrés: una guía práctica. Editorial Kairós.

Vargas, J. (2010). Meditaciones formales adaptadas por el Dr. José Jesús Vargas para la consulta individual Mindfulness y para la enseñanza universitaria y de maestría para la clínica ONELIFE y Escuela Transpersonal, Madrid.

Vargas, J. (2014). Creatividad Mindfulness nueva metodología de estimulación conceptual. [Internet]. Disponible en: https://dialnet.unirioja.es/servlet/libro?codigo=558019 ISBN: 9788470746215. [Acceso: 2019-12-24].

Vargas, J. (2015). Composición Mindfulness, nueva metodología de enseñanza digital de la estética digital consciente, en comunicación visual persuasiva aplicada. [Internet]. Disponible en: http://webs.ucm.es/info/especulo/Narrar en la era digital Especulo 54 UCM 2 015.pdf [Acceso: 2019-12-24].

Vargas, J. (2016). 13 Rutas de atención plena para el liderazgo consciente Perspectiva transformadora e influyente del liderazgo consciente en la comunicación persuasiva. [Internet]. Disponible en: https://dialnet.unirioja.es/servlet/libro?codigo=686663 ISBN: 978-84-15705-12-3. P. 531-554 [Acceso: 2019-24-12].

Vargas, J. (2016). La atención plena basada en la conciencia perceptiva como vínculo pedagógico entre tecnología y educación. [Internet]. Disponible en: https://www.intechopen.com/books/the-evolution-of-mediacommunication/mindfulness-based-on-the-perceptive-consciousness-aspedagogical-link-between-technology-and-educati DOI: 10.5772 / 68085. [Acceso: 2019-12-24].

Vargas, J. (2016). Meditación creativa. 10 pasos 1 templo metodológico de mindfulness para aumentar la creatividad. [Internet]. Disponible en: http://www.redalyc.org/articulo.oa?id=31048901050 [Acceso: 2018-12-24]

Vargas, J. (2018). Comunicación y atención plena en WhatsApp. 8 pilares esenciales de comunicación persuasiva a través de emojis. Ediciones de la Universidad Tecnos. Dentro del trabajo titulado Temas emergentes en innovación universitaria, de la colección de la serie "Ediciones universitarias".

Vargas, J. (2018). Lectura de atención plena. Técnicas para desarrollar una lectura consciente, presente y eficiente a través de la atención plena. IV Congreso Internacional Virtual de Educación Lectora, Universidad de Murcia.

Vargas, J. (2018). Mindfulness Branding: Análisis de las 32 estrategias de comunicación publicitaria más exitosas (1986-2016), en 20 países, y su aplicación comunicativa a Mindfulness. Editorial McGraw - Colina Interamericana de España, S.L. Colección McGraw-Hill Education con (C) 2016 y ISBN 978-84-48612-59-7, 595-603. 
Vargas, J. (2019). Comunicación y atención plena: técnicas efectivas de comunicación con atención plena. En: documento presentado en el II Congreso de mindfulness en educación; 25-27 de abril de 2019; Zaragoza 2019. Póster científico.

Vargas, J. (2019). Metacine. Libro La invención de Hugo. Cinema in the Cinema, ISBN: 978-84-17519-97-1. Ediciones ACCI (asociación iberoamericana de cultura y ciencia), 293-303.

Vargas, J. (2019). Storytelling Mindfulness: programa de narración de cuentos para meditaciones. [Internet]. Disponible en: https://www.intechopen.com/onlinefirst/storytelling-mindfulness-storytelling-program-for-meditations DOI: 10.5772 / intechopen.86778. [Acceso: 2019-12-12].

Wallace, A. (2006). La revolución de la atención. 1st Wisdom ed. Impreso en los Estados Unidos de América.

\section{AUTOR:}

\section{Dr. José Jesús Vargas Delgado}

Profesor Titular en Creatividad y Comunicación Persuasiva del Departamento de Dirección de Empresas, Facultad de Ciencias Sociales, Universidad Europea de Madrid. Director del Máster Universitario en Marketing y Comunicación de la Universidad Europea (2016); Decano de la Universidad Europea de Canarias (2013). Director del Departamento de Publicidad y Contenidos, y Director del Departamento de Comunicación Corporativa en la Universidad Europea de Madrid (2002-2012). Doctor acreditado en Creatividad Publicitaria Gráfica. Licenciado en Publicidad y Relaciones Públicas por la Universidad Complutense de Madrid. Desde el año 2002 ha colaborado con múltiples proyectos turísticos, con la empresa Antar Estrategias. Profesor, desde el año 1999 hasta la actualidad, más de 60 asignaturas impartidas. Profesor en el Máster de Marketing de la Universidad Camilo José Cela. Docente en el Máster en Creación de Contenidos de Telecinco. Profesor del Máster MFA (Master Of Fine Arts) en Tracor. Docente, tutor y miembro de tribunales evaluadores de EAE Business School. Formador "in Company" de en la Consultora IKN Spain e IRR España. Docente del Máster Universidad de Granada. Profesor de IECM y Director de 6 tesis doctorales. Madrid (España).

Google Scholar ID: https://scholar.google.es/citations?user=E8VTKlwAAAAJ\&hl=es Dialnet ID: https://dialnet.unirioja.es/servlet/autor?codigo=2945920

Orcid ID: https://orcid.org/0000-0003-4109-611X

Intechopen ID: https://www.intechopen.com/profiles/204406/jose-jesus-vargasdelgado 